\title{
EFFECTIVE LEARNING FROM DELHI BRTS -A CASE STUDY OF PUNE BRTS
}

\author{
Chetan Kumavat ${ }^{1}$, Harshal Sonawane ${ }^{2}$, Trushik Patel $^{3}$, Xitij Sakhalkar ${ }^{4}$, \\ Anuradha Pansare ${ }^{5}$ \\ ${ }^{1234}$ Student, Department of Civil Engineering, Dr D.Y. Patil Institute of Engineering and Technology, Pimpri, Pune \\ 411018,Savitribai Phule University, Pune, Maharashtra, India.. \\ ${ }^{5}$ Professor, Department of Civil Engineering, Dr D.Y. Patil Institute of Engineering and Technology, Pimpri, Pune \\ 411018, Savitribai Phule University, Pune, Maharashtra, India. \\ Correspondingauthor email: anuradhapansare@gmail.com
}

\begin{abstract}
This paper emphasizes on the common problems endured by Delhi and Pune BRTS corridor. Urban Traffic commutation has an eloquent place in urban life. BRTS is a very old form of public transport, but it is still a new concept for developing countries like India, because of its psychological aspects. Bus Rapid Transit involves synchronized improvements in a transport system's infrastructure, equipment, working, performance and technology that give preference to buses on urban roadways. This paper gives an overall outlook of Delhi and Pune BRT systems and observed some common problems in operating both the system, and some recommendations are mentioned so that could help improving Pune BRTS immensely and influentially and have a better result avoiding bottlenecksthose faced byDelhiBRTS.The main present study intent to highlight the problems and to overcome those problems.
\end{abstract}

Keywords: Delhi and Pune BRTS Bottlenecks, Public Transport, Feeder, Social Image

\section{INTRODUCTION}

A fully effective and truly efficient city on both National and Global levels, it is quiteimportant that the public transit system of that particular city is established in place in an idealized manner [Ananth Rangarajan 2010]. A BRTS is a system which includes specialized design dedicated bus lane and modern infrastructure which helps improve the system quality and reduce the delay in daily routine especially peak hour public transportation country like India[Chaudhari Dron, N.D Hajiani 2014].BRT is basically a combination of the two means of transport that is, thecapacity and speed of metro or light rail with the certain advantages such as lower cost and simplicity of a bus system. In order to have a successful BRT system, it should efficiently work on highlighting some points are to be considered such as: Dedicated bus lane running from the center of the road or the side of the road depending upon the site condition; Offboard fare collection at stations to reduce delay due toboarding and departure; Bus floor and station platform should be on the same level, which could prove ease in getting on and getting off the bus and bus stops. The need of BRTS is evolved in urban and developing cities as it is providing various features such as: Urgent need to transport heavy mass transport volume; Effective mode of transport for low and high income people; fast planning and construction, more flexibility and adaptability; Higher speed with little or no delay for bus; Can operate according to the culture and needs of the city; Environmentally friendly. This could improve the image of public transportation and ease the mode of transport[M. Leal, R.L. Bertini 2006]

\section{Delhi City}

Delhi is the capital city of India,also it the $2^{\text {nd }}$ most populous city in India and $3^{\text {rd }}$ largest urban area in the world.Itspopulation is about 16.3 million.Delhi's road density is about $2103 \mathrm{~km} / 100 \mathrm{~km}^{2}$ in India. Buses are the most important lifeline of road transport,serving to about 60 percent of Delhi's total demand. Delhi has one of the largest bus transport network. State-owned Delhi Transport Corporation (DTC) controls this network, which owns the largest fleet of compressed natural gas (CNG) -fueled buses in the world Personal vehicles. Delhi has the hugevolume of registered cars,Taxis, auto rickshaws and cycle rickshaws compared to any other metropolitan city in India.

In Delhi the vehicles on road have substaintially increased from 3.3 million to 7 million from 2003 to 2011 however, people using private cars are less than $10 \%, 33 \%$ travelling by bus and $30 \%$ walking to work.Also to improve traffic flownew flyovers and underpasses have been constructed,hence thelength of roads in Delhi has increased.Pedestrians became marginalized and journey times and air pollution both increased. In 2002, as per the Supreme Court order issued all diesel buses had converted tocompressed natural gas $(\mathrm{CNG})$ to reduce air pollution. In order to overcome to all above mentioned problem Delhi implemented BRTS (DIMTS).

Exponential increase in personal vehicles: cars in Delhi record decennial growth rate of $92 \%$ (1990-2006) 




In the above graph on Y-axis, it shows the number of vehicles in Millions .

From year 1971 to 2001 Delhi network is increased three times while the vehicles have increased by sixteen times, which have resulted in a massive scramble in road capacity.

\section{HISTORY OF BRT IN DELHI}

\begin{tabular}{|c|c|c|c|}
\hline 2004 & 2005 & 2006-07 & 2008 \\
\hline $\begin{array}{l}\text { A pilot project for } \\
\text { construction of } 6 \mathrm{~km} \text { BRT } \\
\text { corridor conceptualized. }\end{array}$ & $\begin{array}{l}\text { Initiated the work for a } \\
\text { complete stretch (approx } \\
14.5 \mathrm{~km} \text { ) and tenders invited. }\end{array}$ & $\begin{array}{l}\text { Agreement executed between } \mathrm{M} / \mathrm{s} \\
\text { RITES Ltd and contractor in } \\
\text { September. }\end{array}$ & $\begin{array}{l}\text { Work delayed, revised } \\
\text { completion date for first } \\
\text { phase up to Moolchand by } \\
\text { March. }\end{array}$ \\
\hline \multirow[t]{4}{*}{$\begin{array}{l}\text { Transport Department } \\
\text { appointed RITES as } \\
\text { PMC(project Management } \\
\text { consultant) }\end{array}$} & $\begin{array}{l}\text { The Supreme Court ordered } \\
\text { implementation of BRT in } \\
\text { Delhi. }\end{array}$ & $\begin{array}{l}\text { Construction was started in } \\
\text { September. }\end{array}$ & $\begin{array}{l}\text { Work up to Moolchand } \\
(5.8 \mathrm{~km}) \text { completed in } \\
\text { March/April. }\end{array}$ \\
\hline & $\begin{array}{l}\text { EPCA (Environmental } \\
\text { Pollution Control Authority) } \\
\text { was directed to monitor the } \\
\text { progress of the court. }\end{array}$ & $\begin{array}{l}\text { Construction was estimated to be } \\
\text { completed by December } 2007 \text {. }\end{array}$ & $\begin{array}{l}\text { The Complete stretch of } \\
14.5 \mathrm{~km} \text { by December. }\end{array}$ \\
\hline & & $\begin{array}{l}\text { DIMTS (Delhi Integrated Multi- } \\
\text { Modal Transit System)Limited is } \\
\text { entrusted with the responsibility } \\
\text { to manage the operation. }\end{array}$ & $\begin{array}{l}\text { Corridor operation and trail } \\
\text { runs started in } 3^{\text {rd }} \text { week of } \\
\text { April } 2008 .\end{array}$ \\
\hline & & & $\begin{array}{l}\text { RPF (Request for proposal) } \\
\text { for detailed project report } \\
\text { of two more corridors was } \\
\text { released in August. }\end{array}$ \\
\hline
\end{tabular}

\subsection{Outline Of Delhi BRTS}

6 BRT corridors are proposed, which serves a total stretch of $310 \mathrm{~km}$ by the year 2020 . Which will accompany with more than $400 \mathrm{~km}$ of metro train coverage by 2020 and further coverage by Monorail and Light Rail. It was in operation in April 2008. There were in all 9 bus stops. Ridership in peak hour was 6500 passengers/hr/direction and 120 buses/hr. Commercial speed of buses in BRT corridor was about 16$19 \mathrm{~km} / \mathrm{hr}$ and that of buses outside BRT corridor was 7$11 \mathrm{~km} / \mathrm{hr}$. The cost required cost to setup the entire infrastructure was about Rs 14 crore $/ \mathrm{km}$ (3million $/ \mathrm{km})$. Average user Fare: Rs 1/km Rs3.87 per passenger (DIMTS). 


\subsection{Delhi BRT corridors}

\begin{tabular}{|c|c|c|}
\hline $\begin{array}{l}\text { SR.No. } \\
\text { BUS }\end{array}$ & CORRIDORS Length (Km) & $\begin{array}{l}\text { TOTAL } \\
98 \sim 100 \mathrm{Kms}\end{array}$ \\
\hline 1 & $\begin{array}{l}\text { Nangloi - Peeragarhi - Punjabi Bagh - Anand Parbat -Rani Jhansi Road - Link Road - Gole Market } \\
\text { - Shivaji Terminal. }\end{array}$ & $20 \mathrm{~km}$ \\
\hline 2 & $\begin{array}{l}\text { Azadpur - Wazirpur Industrial Area - Punjabi Bagh - Raja Garden - Naraina Vihar - Dhaula Kuan } \\
\text { - Moti Bagh - South Extn. - Mool Chand - LSRC - Nehru Place }\end{array}$ & $32 \mathrm{~km}$ \\
\hline 3 & $\begin{array}{l}3 \text { Jahangirpuri - Azadpur - Rana Pratap Bagh - Malkaganj - St. Stephen’s Hospital - Mori Gate - } \\
\text { Old Delhi Rly. Stn. }\end{array}$ & $12 \mathrm{~km}$ \\
\hline 4 & $\begin{array}{l}4 \text { Dr. Ambedkar Nagar - Masjid Moth - Mool Chand - Sundar Nagar - Appu Ghar - Delhi Gate - } \\
\text { Lal Qilla - ISBT }\end{array}$ & $19 \mathrm{~km}$ \\
\hline 5 & $\begin{array}{l}5 \text { Anand Vihar - Karkarduma Chowk - Swasthya Vihar - Lakshmi Nagar - ITO - Bara Khamba } \\
\text { Road - Shivaji Terminal }\end{array}$ & $15 \mathrm{~km}$ \\
\hline Total & & $98 \sim 100 \mathrm{~km}$ \\
\hline
\end{tabular}

\subsection{DESIGNING ISSUES}

Building of new infrastructure and modification of new and existing once need the implementation in BRT systems.

- The shift is required in certain minor structures and electrical installations.

- Site conditions should determine the position of lanes.(center or side).

- Bus lanes should remain at grades on the side with an adequate weaving length at existing flyovers.

- Provisions for splitting of flyovers to permit center bus lanes

\subsection{ENVIORNMENTAL ISSUES}

- Diesel engine buses cause serious air pollution levels, noise and vibration.

- The system could nullify price penalty of installing overhead lines, environmental benefits potential for saving of centrally generated electricity, especially in cities where electricity is less expensive source than other power sources.

- In addition, most trolleybus applications can be converted to light rail with the only extra expense being lying and maintenance of tram tracks in the street.

\subsection{Major Problems Of Delhi Brts Which Can Also}

\section{Be Arise Or Arising In Pune Brts.}

- LongTraffic signal cycle (4 minutes in the peak hour)

- Long queuesare experienced by general traffic lanes.

- Some passengers aligning and boarding outside the platform because the bus queuing were longer than the station platform length.

- The operation of the bus lanes and the station was affected by the bus breakdown.

- Pedestrian carelessness(i.ejaywalking etc.)

- Bus lanes was also encroached by some motor vehicle.
- Especially in the peak period the bus occupancy levels were high

- High variability in intervals and commercial speeds were displayed by bus operating.

- Bicycle tracks were also encroached by two wheelers to jump the motor vehicle queues.

\subsection{SHUTDOWN}

The haphazard increment of air pollution in Delhi dueto vehicles that a trial run was started by Delhi government as an odd-even formula, still commuters witnessed massive traffic jams along the BRT corridor.

Dismantling of the BRT corridor, Moolchand to Ambedkar Nagar(5.8-km), was begun on 19 January 2016 \& the corridor was completely dismantled by February (DIMTS) The BRT corridor was built in 2008coasted aroundRs 180 crore. The dismantling of the BRT corridor cost around Rs 12 crore. To avoid this crucial situation and to put Pune BRT on the positive side, Pune should take initiative to improve the system and pedestrian safety as their major priority. As BRTS in Pune city is at a very young stage there are a large scope of improvements. As after BRT implementation, there is no large difference made due to BRT functioning.

\section{LIMITATIONS OF PUNE BRTS}

PMPML BRTs in theinitial stage is considered as huge successes, though there are some zones where BRTs could improve to do better.

- Bus Shelters were in the road middle, so while crossing the road after getting-off or before boarding cause inconvenience (PMPML)

- PMPML has proposed four new corridors, for this PMPML will have to acquire at least 700 special buses, but as of now, PMPML is serving on 350 such buses.

- Another problem is that the BRTS track is being introduced at already existing city which has caused a lot 
of disturbance on the road and have affected mixed traffic. Due to the introduction of the separate bus way in the road midwayhas reduced the road width and jammed the mixed traffic.

- A Lack of level boarding, mismatch in bus stop heights and busdesign, lacking drivers skills ,lack of training workshops.
- No Corridor enforcement.

- The Corridor is discontinuous at many places.

- Fairly good cycling and walking infrastructure on the bus corridor.

- No space for bicycle parking, Auto Rickshaw parking, vending along the corridor.

\subsection{Common Problems In Delhi BRT And Pune BRT}

\begin{tabular}{|l|l|}
\hline PROBLEMS & SOLUTIONS \\
\hline General traffic lanes experienced long queuing. & $\begin{array}{l}\text { The Device should be implemented on the bus and also on the traffic } \\
\text { signal so that when the bus reaches at a distance of 300m-500m from } \\
\text { signal, the signal should automatically turn red to stop the general } \\
\text { traffic and allow BRTS buses to move uninterruptedly and as soon as } \\
\text { the bus crosses the signal the signal should automatically turn green } \\
\text { for mixed traffic. }\end{array}$ \\
\hline $\begin{array}{l}\text { Operation of the bus lanes and the stations was was } \\
\text { affected by bus breakdown }\end{array}$ & $\begin{array}{l}\text { Proper communication system (ITMS) between buses and bus stops } \\
\text { should be there, so that the bus stops \& buses coming from behind } \\
\text { can take proper measures so as to avoid traffic and delays. }\end{array}$ \\
\hline Pedestrian jaywalking was common. & Skyways or subways should be provided. \\
\hline Some motor vehicles encroach the bus lanes. & Wardens should be appointed at every junction. \\
\hline $\begin{array}{l}\text { High levels ofBus occupancy, especiallyduring } \\
\text { peak period. }\end{array}$ & Frequency should be increased. \\
\hline $\begin{array}{l}\text { Bicycle tracks encroachment by two wheelers to } \\
\text { jump motorbikes queues. }\end{array}$ & Proper enforcement should be provided on the bicycle track. \\
\hline
\end{tabular}

\section{RECOMMENDATIONS}

1. BRT systems not to be treated as an exclusive system. Need to integrate existing systems with the new systems in terms of physical access, ticketing and governance mechanisms.

2. Adapting BRT in different ways in Indian cities, rather than one defined prototype.

3. BRS should be integrated with other means of public transport for better capacity carriage and to cut down the use of personal vehicles.

4. Lower and middle income groups are the most dedicated and captive bus commuters in big cities. Is it possible for BRT to make it more accessible to these groups by cutting down the ticket cost? The cost of BRT tickets can exclude people and discourage the use of it.

5. Designing emphasis on pedestrian access to BRT stations.

6. Fedder services should be provided free.

7. Constant review of public should be taken to make improvement in the system if any.

8. BRTS must be effective in lessening the number of urban private vehicles.Commuters should rely on BRTS as thebest solution for public pooling relieving burden on urban road networks especially in peak congestion hours.All necessary actions for making BRTS punctual, efficient, comfortable, commuter friendly and hassle free careful planning and running should be done by local authorities.

\section{Need of improvements}

1. Local Connectivity to BRTS Bus Stops - Shared Auto service (similar to outside Mumbai Railway Stations on per seat basis) should be encouraged to-from the BRTS Bus Stops. Today, many BRTS routes like AundhRavet, Wakad-Bhosari traverse through low density areas while the adjoining inner areas are densely populated instead (e.g. Pimple Saudagar, Aundh Parihar Chowk, Wakad Dutt Mandir Rd, Kaspate Vasti Road etc.)Which means, commuters will have to travel for a $1 \mathrm{KM}$ or more at least to reach the nearest BRTS Bus stop. Also Traffic Police has made 'No Parking' Zones on both sides of BRTS route, thus making someone difficult to travel by own vehicle, park near the Bus Stop and travel further. BRTS Parking have been provided for select stops but they are limited.

2. Ease of Access - BRTS bus-stops have been constructed far away from the junctions while old busstops used to be at convenient locations. Commuters have to walk more to reach the bus stops.

3. Optimize Routes based on Traffic PatternsOrganize the Bus routes \& their schedule considering the Commuter demands, density, Traffic Patterns, Peak time, etc. BRTS Wardens / personnel deployed at the Bus Stops can play vital role in informing about the traffic density and consumer needs. E.g. 'Katraj - 
Hinjewadi' Or 'Nagar Rd - Hinjewadi' (Via Shivaji Nagar, Aundh, Dange Chowk) long bus routes can be introduced because there would be traffic both-ways all the times. We can have Bus for every 5-10 min and still it would be full both ways.

4. Maintain same look \& Feel for Buses - Today there are a variety of buses of different shapes, sizeand makes with PMPML. Buses on BRTS route should have standard color, signage and avoid painting / pasting advertisements on the whole bus body. It looks very ugly. Only certain placeholders should be made available for posting the advertisements to earn revenues. LED screens inside the Bus can also be a mode to earn revenues through advertisements. There should be strict penalties for posting unauthorized banners on BRTS property, including buses and for mutilation or damage to bus stops

5. Cleanliness - Buses are hardly cleaned from inside / outside. We should use pressure Jets (which consumes less water) to clean the bus every night from inside-out before it is deployed on the route. There has to be an inspector whose responsibility should be to check if the Bus deployed on the route in the morning has (1) been cleaned from Inside \& outside (2) LED Displays are working fine and are properly set (3) No Mechanical faults (4) Tyre Pressure / treads, Fuel, Battery etc. is all Ok.

6. Professional Attitude - BRTS routes should be run and managed professionally. That includes continuous trainings for the drivers, conductors and other staff. Authorities can organize tours / workshops to other domestic Cities like Mumbai (BEST), Bangalore (Vayu Vajra) and Ahmadabad (JanMarg) where their Bus services have been rated as the best. We should adopt to the best practices followed in the domestic public transport sector across Cities before arranging for fancy tours overseas.

7. BRTS should have Own Depots - BRTS should have dedicated Bus Depots where Buses can be parked; cleaned and basic maintenance can be carried out.

8. Commuter Crossings on Road should be lighted Commuter Crossing (raised pathway to cross the road) near BRTS Bus Stops should be illuminated from Top or from the side so that Pedestrians who are crossing the road are clearly visible to motorist from a distance in the night. There should be signboards and blinking lights (besides traffic signal what we have today) to indicate the pedestrian crossing.

9. Surprise visits / Inspections are needed - Introduce uniformed TC (Ticket Checker) to inspect the tickets, bus stops and also to address the need for additional buses during peak hours. This is to establish tighter control and discipline on people who manage the BRTS and commuters who use them.
10. Improve frequency and timings - Frequency especially for long route buses should be increased and BRTS bus route should be open at least till 12 AM in the night. In fact, there should be round-the-clock bus service connecting to Train stations (Pune Station, Shivaji Nagar) and Airport with the rest of the City. The real need of public transport for travelers is during peak hours.

11. Reduce BRTS signal to $\mathbf{1 0}$ Sec - New BRTS signal installed at every Junction is creating traffic Jams for people who wants to take a right turn at the junction e.g. Sai Chowk @ Pimple Saudagar. Instead, BRTS signal should be reduced to $10 \mathrm{Sec}$ (allowing only buses stopped at the Signal to cross) thus making remaining 20 Seconds added extra for the right turn signal.

\section{CONCLUSION:}

1. BRT deserves in the corridor that already have the highest transit ridership in integration with other integral commutation mean of transportation.

2. Planning and implementation both has its own role in making BRT more successful and efficient and reliable. Node selection its peak hour vehicle count like two wheeler and four wheeler impacts on signal timing. If those are not correctly count and update in due course of period, it may lead to traffic congestions at junctions.

3. The Feeder network must be evaluated as per commuters demand.Feeder will immensely impact on profitability of BRTS.

4. Peak hour BRTS trips should be distinguishly decided. More precise calculations should be done. The number of commuters on weekdays, on weekends, the area which having other means of commutations, number of service lanes, importance of nodes of BRT on the local map.

5. No commuters like change in means of commuting until reaches to final destination, so transit managers should give design such routes to commuters need not to change buses often. Learn their transportation needs, pattern of travelling, selection of bus stops and distances between same pick-up hours, frequencies, delays, much more than amenities and boarding. The system's reliability is the most critical issue for riders.

6. The fare collection system that one chooses to incorporate into the BRT must be flexible and adaptable to future needs and provide seamless travels across all modes of service being operated. Often riders or operations need change, so it's important that fare collection can adapt to new business rules.

7. Riders should know about the delays, when the next bus will arrive, any schedule changes, and more. Real time information at stations is important.

8. Rather smartphone applications may be the solution of real-time information updating.

9. Critical and correct management and implementation of the BRT system is necessary from the point of view of safety and disaster management. This allows better fleet management that translates into benefits on end users. 
10. Access and dependability are crucial for a successful BRT system. The first and last mile is the toughest for the BRT newbies, so support riders with way-finding signs and interactive kiosks on platforms that guide riders to local attractions.

11. Safety at BRTS routes and private vehicles crossing should be prioritized at most which can be digital instrument controlled and directed as per requirement.

\section{REFRENCES:}

[1]. Chaudhari Dron, N.D Hajiani (2014). "Traffic Impact Analysis of BRTS - A Case Study of Ahmedabad BRTS" IJEDR, Volume 2, Issue 2, ISSN: 2321-9939

[2]. Ananth Rangarajan (2010). "BRTS- Bus Rapid Transit System in Pune: Modeling, Simulation and Feasibility Analysis." International Conference on Industrial Engineering and Operations Management, 781.

[3]. Mehata and associates (2006). "DPR on Indore Bus Rapid Transit system under JNNURM."

[4]. M. Leal, R.L. Bertini(2006), "Bus Rapid Transit: An Alternative for Developing Countries"Compendium of Technical Papers.

[5]. Census of India; Government of India; Ministry of Home Affairs., www.censusindia.net

[6]. Delhi Integrated Multi-Modal Transit System Limited (DIMTS), www.dimts.in.

[7]. Institute for Transportation and Development Policy (ITDP); USA /Europe /Brazil /India /China / Mexico.

[8]. Jawaharlal Nehru National Urban Renewal Mission (JNNURM); Sub Mission-1; www.jnnurm.nic.in

[9]. Pune Mahanagar Parivahan Mahamandal Limited (PMPML), www.pmpml.org

[10].Pune Vehicle Activity study; University of California at Riverside; Global Sustainable Systems Research

[11].tripp.iitd.ernet.in/delhibrts/brts/hcbs/hcbs/BRTdesignsu m.pd

[12].https://en.wikipedia.org/wiki/Bus_rapid_transit

[13].https://en.wikipedia.org/wiki/Delhi

[14].https://en.wikipedia.org/wiki/Delhi_Bus_Rapid_Transit _System\#History 